\title{
Influence of Thermomagnetic Treatment on Magnetoelastic Properties of FeNiMoB Amorphous Alloy
}

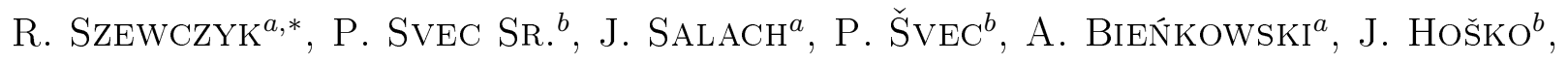 \\ D. JACKIEWICZ ${ }^{a}$, M. KAMIŃSKI ${ }^{c}$, W. WINIARSKI ${ }^{c}$ \\ ${ }^{a}$ Institute of Metrology and Biomedical Engineering, Warsaw University of Technology \\ 'sw. A. Boboli 8, 02-525 Warszawa, Poland
}

${ }^{b}$ Institute of Physics, Slovak Academy of Sciences, Dúbravská cesta 9, 84511 Bratislava, Slovak Republic ${ }^{c}$ Industrial Research Institute for Automation and Measurements, Al. Jerozolimskie 202, 02-486 Warsaw, Poland

\begin{abstract}
Paper presents the results of magnetoelastic tests of ring-shaped cores made of $\mathrm{Fe}_{40} \mathrm{Ni}_{38} \mathrm{Mo}_{4} \mathrm{~B}_{18}$ amorphous alloy. The cores were subjected to thermomagnetic annealing under different values of magnetic field. The obtained results enabled us to connect the magnetoelastic characteristics of $\mathrm{Fe}_{40} \mathrm{Ni}_{38} \mathrm{Mo}_{4} \mathrm{~B}_{18}$ amorphous alloy with the conditions of thermomagnetic treatment of the material.
\end{abstract}

DOI: 10.12693/APhysPolA.126.52

PACS: $75.80 .+\mathrm{q}, 75.50 . \mathrm{Kj}$

\section{Introduction}

Rapidly quenched, amorphous $[1,2]$ and nanocrystalline [3] alloys are widely used as the cores of inductive components for switching mode power conversion, current transformers [4] as well as cores of mechatronic sensors [5]. For all these applications, the specific, magnetic properties are required. These properties of amorphous alloys can be determined by its thermomagnetic treatment [6].

On the other hand, magnetoelastic properties of amorphous alloy are very important from practical point of view. Especially for miniaturized components, even relatively small forces may generate significant stresses, causing decreasing of core permeability up to $65 \%$ [7].

In spite of the fact that the influence of thermomagnetic annealing on both, magnetic properties of amorphous alloys as well as its magnetoelastic properties were recently intensively investigated, these properties are still not linked together. This paper is starting the process of filling this gap.

\section{Method of investigation}

For the magnetoelastic tests, three ring-shaped cores made of $\mathrm{Fe}_{40} \mathrm{Ni}_{38} \mathrm{Mo}_{4} \mathrm{~B}_{18}$ amorphous alloy were used. The cores had the outside diameter of $32 \mathrm{~mm}$, the inside diameter of $25 \mathrm{~mm}$ and the height of $10 \mathrm{~mm}$. All tested cores were annealed at $280{ }^{\circ} \mathrm{C}$ for one hour. During the annealing, the cores were subjected to magnetic field perpendicular to the base of the core. The field strength was $0 \mathrm{kA} / \mathrm{m}, 200 \mathrm{kA} / \mathrm{m}$ and $340 \mathrm{kA} / \mathrm{m}$ respectively.

*corresponding author; e-mail: szewczyk@mchtr.pw.edu.pl

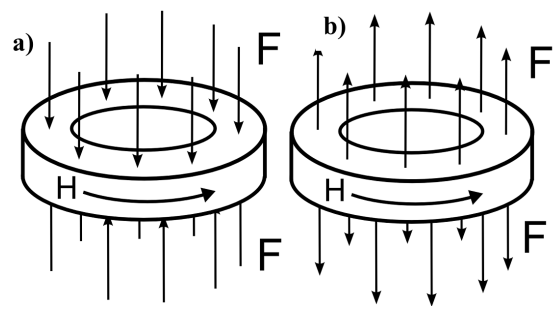

Fig. 1. Method of application of the uniform stresses to the tested ring-shaped core: a) compressive, b) tensile.

External forces, both compressive and tensile, were applied perpendicularly to the base of the core (Fig. 1). Special system of non-magnetic backings [5] was used to enable core to be wound by both magnetizing and sensing windings. Magnetoelastic characteristics were measured by digitally controlled hysteresisgraph.

\section{Results and conclusion}

The results of testing of the influence of both compressive and tensile stresses $\sigma$ on the hysteresis loop $B(H)_{\sigma}$ of $\mathrm{Fe}_{40} \mathrm{Ni}_{38} \mathrm{Mo}_{4} \mathrm{~B}_{18}$ alloy are presented in Fig. 2. The changes of the maximal flux density $B_{m}$, as the function of stresses $\sigma$, for a given magnetizing field $H_{m}$, are presented in Fig. 3.

For all tested cores, under the influence of compressive stresses, the value of flux density $B$ in the sample increases, whereas under the tensile stresses - it decreases. This effect is connected with the positive value of magnetostriction of $\mathrm{Fe}_{40} \mathrm{Ni}_{38} \mathrm{Mo}_{4} \mathrm{~B}_{18}$ amorphous alloy. Moreover, the stress sensitivity is higher, for lower values of magnetizing filed $H_{m}$, due to the higher participation of magnetoelastic energy in total free energy of the tested cores. 


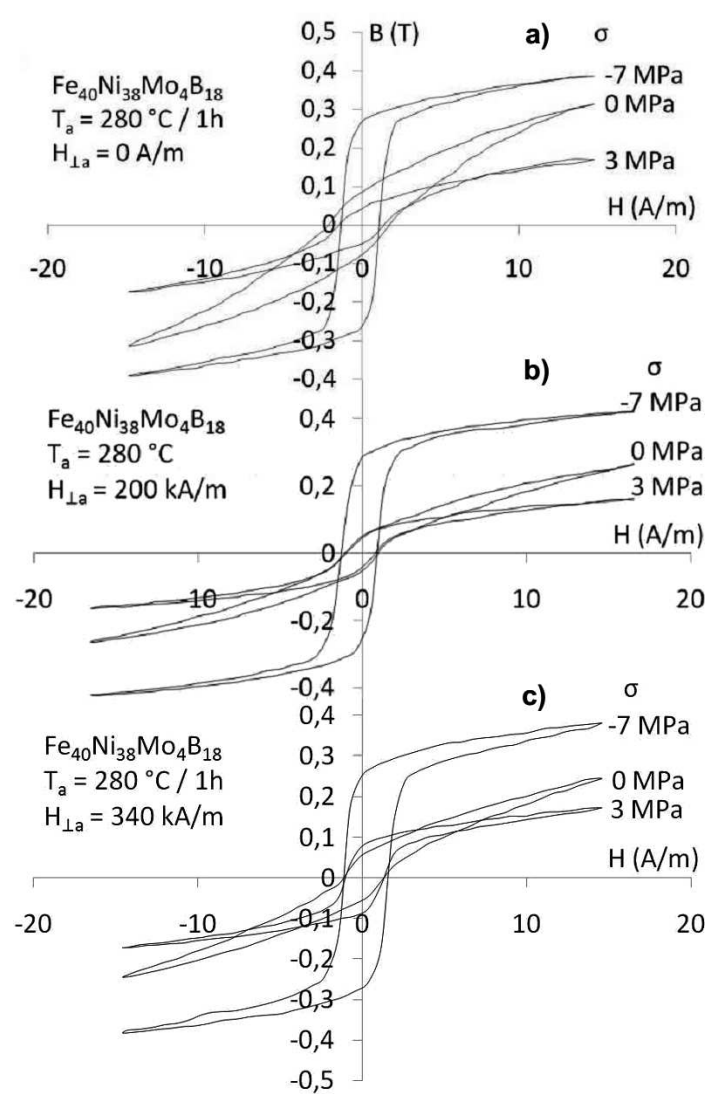

Fig. 2. Influence of stresses on $\mathrm{B}(\mathrm{H})$ hysteresis loops of $\mathrm{Fe}_{40} \mathrm{Ni}_{38} \mathrm{Mo}_{4} \mathrm{~B}_{18}$ amorphous alloy subjected to annealing in perpendicular magnetic field: a) $0 \mathrm{kA} / \mathrm{m}, \mathrm{b}$ ) $200 \mathrm{kA} / \mathrm{m}, \mathrm{c}) 340 \mathrm{kA} / \mathrm{m}$.

\section{Acknowledgments}

The support of the bilateral project APVV-Sk-PL0043-12 is acknowledged from Slovak side.

\section{References}

[1] R. Hasegawa, J. Non-Cryst. Solids, 287, 405 (2001).

[2] Z. Stoklosa, K. Rasek, P. Kwapulinski, G. Badura, G. Haneczok, L. Pająk, J. Lelątko, A. Kolano-Burian, J. Alloys Compd. 509, 9050 (2011).

[3] A. Kolano-Burian, L. Varga, R. Kolano, T. Kulik, J. Szynowski, J. Magn. Magn. Mater. 316, E820 (2007).

[4] J. Salach, L. Hasse, R. Szewczyk, J. Smulko, A. Bieńkowski, P. Frydrych, A. Kolano-Burian, IEEE Trans. Magn. 48, 1493 (2012).

[5] R. Szewczyk, A. Bieńkowski, Sens. Actuators A 110, 232 (2004).

[6] I. Skorvanek, J. Marcin, T. Krenicky, J. Kovac, P. Svec, J. Magn. Magn. Mater. 304, 203 (2006).

[7] B. Peng, W.L. Zhang, Q.Y. Xie, W.X. Zhang, H.C. Jiang, J. Non-Cryst. Solids 365, 59 (2013).

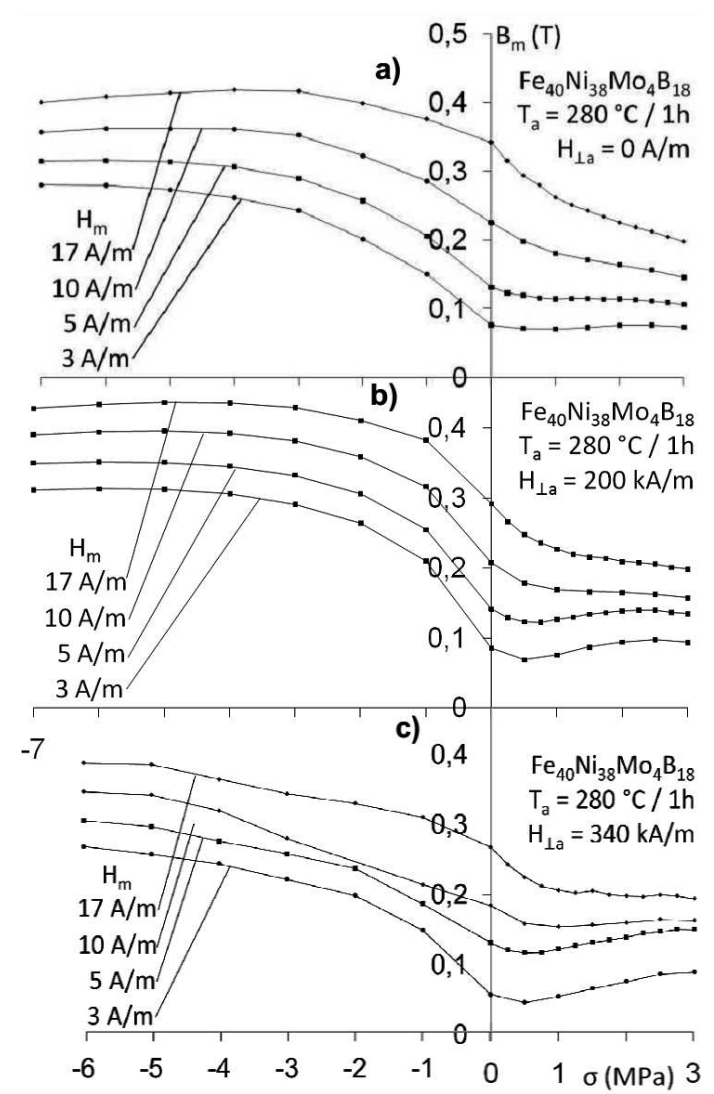

Fig. 3. $B(\sigma)_{H m}$ characteristics of $\mathrm{Fe}_{40} \mathrm{Ni}_{38} \mathrm{Mo}_{4} \mathrm{~B}_{18}$ amorphous alloy subjected to annealing in perpendicular magnetic field: a) $0 \mathrm{kA} / \mathrm{m}$, b) $200 \mathrm{kA} / \mathrm{m}$, c) $340 \mathrm{kA} / \mathrm{m}$. 